\title{
SUBSTANTIATION OF APPLICATION OF THE STRATEGIC PLANNING METHODS IN ORDER TO IMPROVE EFFICIENCY OF THE AUTOMATED SYSTEMS OF FIRE AND EXPLOSION PROTECTION AT THE FUEL AND ENERGY COMPLEX FACILITIES IN THE SPECIAL CONDITIONS
}

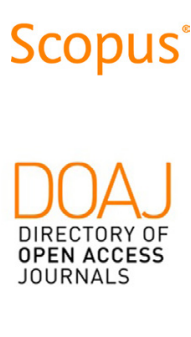

Crossref

\section{Andrey Strogonov}

Gubkin Russian State University of Oil and Gas, Faculty of Integrated Security of the Fuel and Energy Complex, Department of Cryptology and Algorithms, Moscow, Russian Federation

\section{Nikolay Topolskiy}

Academy of the State Fire Service of the Ministry of the Russian Federation for Civil Defense, Emergencies and Elimination of Consequences of Natural Disasters, Department of Information Technology, Moscow, Russian Federation sity of Oil and Gas, Faculty of Integrated Security of the Fue and Energy Complex, Moscow, Russian Federation

\section{Aleksey Kruchkov}

Gubkin Russian State University of Oil and Gas, Faculty of Integrated Security of the Fuel and Energy Complex, Department of Complex Security of Critical Facilities, Moscow, Russian Federation

Key words: planning of the fire safety measures, continuous function, fire extinguishing equipment, fire safety

doi:10.5937/jaes0-30258

\section{Cite article:}

Samarin, I., Grinyaev, S., Strogonov, A., Topolskiy, N., Kruchkov, A. (2021) SUBSTANTIATION OF APPLICATION OF THE STRATEGIC PLANNING METHODS IN ORDER TO IMPROVE EFFICIENCY OFTHE AUTOMATED SYSTEMS OF FIRE AND EXPLOSION PROTECTION AT THE FUEL AND ENERGY COMPLEX FACILITIES IN THE SPECIAL CONDITIONS, Journal of Applied Engineering Science, 19(3), 667-675, DOI:10.5937/jaes0-30258 


\title{
SUBSTANTIATION OF APPLICATION OF THE STRATEGIC PLANNING METHODS IN ORDER TO IMPROVE EFFICIENCY OF THE AUTOMATED SYSTEMS OF FIRE AND EXPLOSION PROTECTION AT THE FUEL AND ENERGY COMPLEX FACILITIES IN THE SPECIAL CONDITIONS
}

\author{
Ilya Samarin ${ }^{1 *}$, Sergey Grinyaev², Andrey Strogonov ${ }^{3}$, Nikolay Topolskiy ${ }^{4}$, Aleksey Kruchkov ${ }^{5}$ \\ ${ }^{1}$ Gubkin Russian State University of Oil and Gas, Department of Automation of Technological Processes, \\ Moscow, Russian Federation \\ ${ }^{2}$ Gubkin Russian State University of Oil and Gas, Faculty of Integrated Security of the Fuel and Energy \\ Complex, Moscow, Russian Federation \\ ${ }^{3}$ Gubkin Russian State University of Oil and Gas, Faculty of Integrated Security of the Fuel and Energy \\ Complex, Department of Cryptology and Algorithms, Moscow, Russian Federation \\ ${ }^{4}$ Academy of the State Fire Service of the Ministry of the Russian Federation for Civil Defense, \\ Emergencies and Elimination of Consequences of Natural Disasters, Department of Information \\ Technology, Moscow, Russian Federation \\ ${ }^{5}$ Gubkin Russian State University of Oil and Gas, Faculty of Integrated Security of the Fuel and Energy \\ Complex, Department of Complex Security of Critical Facilities, Moscow, Russian Federation
}

This paper presents substantiation of the obligatory application of the strategic planning methods in order to improve efficiency of the automated systems of fire and explosion protection (ASFEP) at the facilities of the fuel and energy complex (FEC) in the special conditions. To this end, the technological production process of the FEC facilities is divided into destructive and creative subprocesses. It is assumed that the events that cause the potentially dangerous situations, which are connected with fires and explosions, form the destructive subprocess. The activities, which are carried out within the framework of fire safety plans at the FEC facilities and which are controlled by the shift on duty, form the creative subprocess. Events of the first subprocess reduce efficiency of the ASFEP, while events of the second subprocess increase efficiency of this system. Authors of the article propose the continuous curve of recovery of the ASFEP efficiency in order to ensure modelling the type of influence of various rehabilitation measures. Two kinds of the exponential functions enveloping the moments of fire and rehabilitation are analysed for these subprocesses. The article describes the graph of actual rehabilitation of the ASFEP efficiency taking into account assumptions concerning nature of these functions. It was established that management of the relevant measures, which is determined with the help of the strategic planning methods, is the most significant parameter in this model.

Key words: planning of the fire safety measures, continuous function, fire extinguishing equipment, fire safety

\section{INTRODUCTION}

Prevention of the dangerous situations, which can become the reasons of fires and explosions at the facilities of the fuel and energy complex (FEC) is largely dependent on compliance with various safety measures and on application of the state-of-the-art fire-fighting systems [1, 2]. Operational management of various measures of the fire safety (FS) is the important direction of activity of the duty shifts at the FEC enterprises. There are no doubts that this operational management determines the outcome of the abnormal situation, which has occurred at the object of fire protection. In order to increase level of awareness and make necessary decision, new practices are proposed. These procedures ensure the quickest finding of the source of ignition, as well as elimination of ignition in the real-time mode taking into account the rate of development of fires [3-5]. However, timely elaboration of the full-fledged plan, which would ensure the required level of the FS at the enterprise, as well as timely approval of this plan by the responsible executives, would decrease the risk of possible financial loss and loss of property or would decrease the degree of damage. This is highly topical issue for the FEC enterprises, for which this damage can become the problem of critical importance. Thus, for instance, in 2012 the largest petroleum processing plant of Venezuela (Amuay Oil Refinery) shut down its operation completely for some time. Because of this tragedy, 41 persons were died and more than 80 persons were injured [6].

In the course of investigations in respect of organisation of the processes of planning at the FEC objects, it was established that planning of the FS measures is performed within the framework of the supplementary production process for the FS maintaining [7, 8]. In doing so, the planning as such is performed in the course of general measures for planning the output of the prod- 
ucts and performance of the supporting measures for this process. Performance of the measures, which were planned in such a manner, is controlled by the duty shift in the course of the operational management of the FEC object. In addition, the duty shift performs monitoring of these measures.

In this case, it should be noted that in the course of performance of the current measures by the duty shift, it is usual that this duty shift reveals certain nonconformities between the planned parameters of control over performance of various plans and those parameters of control, which are actually measured in practice. In this case, it is possible to reveal the most common disadvantage, which is connected with the fact that actual time of performance exceeds the previously planned time of performance of certain operations. Such exceedance can be caused by various reasons. Another common departure from provisions of the plans is connected with occurrence of new circumstances in the course of performance of various fire safety measures. These circumstances can result in the start-up of new processes (for instance, purchase of equipment or search of the sources of financing), which were not envisaged by the existing system of plans of the relevant enterprise.

In the latter case, it is also possible to say on the possible reciprocal adjustment of plans of several subsystems of the automated system of fire and explosion protection (ASFEP) [9]. These subsystems will start-up various cycles of management of various subsystems. Taking into account general scale of planning, as well as taking into consideration the ASFEP composition, such adjustments in the plans of operation of the certain subsystems of the ASFEP cannot occur as the processes, which are isolated from the entirety of plans of the FEC object. That is why it is necessary to develop the scientifically based mechanism of such adjustments, provided that such mechanism would make it possible to ensure planning process taking into account the general strategic goals. As of the FEC object, such strategic goal would be manufacture of the necessary volume of products. As of the ASFEP of the FEC object, such strategic goal would be maintaining of the required level of fire and explosion protection within this object.

In this connection, we can mention that in the course of monitoring of the FS maintaining plans, as well as in the course of control over these plans, it is already possible not only to reveal nonconformities, but also to find and register prerequisites of occurrence of the dangerous situations. Thus, for instance, in the course of the evaluative measures, which are performed by the supporting tools of the ASFEP management, with the help of the specialised software applications it can be established that it is necessary to replace certain irrigators in order to ensure sustainable operation of the entire fire-fighting subsystem in the case of fire [10]. To do so, it would be necessary to perform certain FS measures, which are not included to the general plan of the FS maintaining. If relevant contract was concluded with the organisation, which performs service maintenance of the fire-fighting system of the FEC object, then it can be a routine procedure. In a reverse situation, it would be necessary to initiate process of installation of new irrigators in the right locations. It would be necessary to ensure that such rehabilitation process would envisage availability of the relevant technical equipment, as well as installation and tests both of the replaced components, and of the entire system. In this case, it is highly likely that these measures must be financed from the additional sources. To that end, it would be necessary to envisage additional planning of, monitoring of, and control over all the measures within the framework of the general goal, that is, it would be necessary to ensure maintaining of the required level of efficiency of the fire-fighting system of the FEC object [11].

This particular example indicates that in the course of performance of the FS measures in accordance with the technological process of the FS maintaining at the FEC object there exist two subprocesses, which are directed in the opposite sides from the point of view of the ASFEP efficiency. The first subprocess is connected with occurrence of the prerequisites for occurrence of the dangerous situations and registration/logging of these prerequisites by the duty shift of the object in the course of the operational activity at the FEC object. This subprocess results in the decrease in efficiency of the FS measures within the ASFEP. The second subprocess is connected with performance of the corrective actions, which ensure rehabilitation of efficiency of the ASFEP components at certain directions. This subprocess has a relationship to the planning and financing, as well as it is connected with the general process of planning, while this general process has a relationship to the strategic planning at the entire enterprise. Both these subprocesses consist of the measures, which are performed during a certain unit time and which have the prescribed efficiency in respect of the entire ASFEP.

In order to estimate possibility of construction of the general model for assessment of efficiency of the ASFEP operation in usual conditions and in the special conditions, let us remind the following statement: "efficiency is the relationship between the achieved result and the resources, which were utilised" [12]. As a rule, in order to perform assessment of the ASFEP efficiency, various measures of efficiency are utilised. However, there are quite a lot of various directions of activity within the ASFEP. These directions of activity have different dimensionalities and various physical significances, but at the same time, they can be modelled/simulated in respect of various assessments in the same manner. Therefore, we will select conventional dimensionless units of measurement, that is, we will consider that efficiency of the entire ASFEP is determined by the certain aggregate indicator of efficiency. In this case, the following ideal situation is possible: it is necessary to ensure normalisation/valuation of the measurable efficiency of the ASFEP in respect of the certain maximum possible value of this efficiency. 


\section{MATERIALS AND METHODS}

The automated system of fire and explosion protection (ASFEP) of the FEC objects is the subject of the present investigation. This ASFEP was described earlier (in another presentation) in the article [11]. The present article contains detailed description of assessment of efficiency of the ASFEP functioning. There are no doubts in respect of importance and topicality of such process at the enterprises of all branches of the FEC. This subject of investigation is analysed in the context of planning of the measures that ensure the FS maintaining. This article describes in detail a variant of modelling efficiency of the FS measures and efficiency of the entire ASFEP. It contains description of characteristics of those events, which exert influence upon the ASFEP efficiency. In addition, the article presents the events along with the certain restrictions, which are connected with the special conditions, which exert influence upon the quality of assessment of the ASFEP efficiency. The article proposes to use analytical tools of the strategic planning, which increases quality of support to management and compensates for decrease in the ASFEP efficiency due to occurrence of such restricting special conditions.

Further discussions and conclusions are based on the theoretical level of cognition. The mathematics scientific theory is used as the form of the scientific knowledge. The methods, which are used both at the empirical lev$\mathrm{el}$, and at the theoretical level (the so-called universal methods of cognition), are applied. One of them is the abstraction technique. It is the method of the theoretical generalisation, which is based on identification of those aspects of the object under investigation, which are important for the researcher, as well as on rejection of those properties, which are insufficient for the researcher. Modelling is another method, which is based on construction and investigation of the models of actual processes. This method is frequently applied along with other methods. Model is the subsidiary object, which was transformed in cognitive purposes and which provides new information, which is required for analysis of the main object. The sign (information) mathematical simulation is used within the present article.

There are many various methods, which are related to the theoretical investigation only. However, in the course of selection of the method for solving the posed problem, we have come to conclusion that method of formalisation is the more comprehensive method in respect of the statement of the problem under investigation. Such formalised system is used for simplification of the subject of investigation. This simplification, in its turn, results in acceleration of obtaining the expected result. In order to construct the main model, it is necessary to formalise the subject of investigation (to provide the subject with a certain form), as well as to envisage nomination of this subject with the help of a certain set of signs. It is possible to perform both these operations with the help of the formalisation method.
At the first stages of modelling, we have to determine dependence of the aggregate indicator of the ASFEP efficiency from the maximum, required, and critical efficiency. Because of significances of the FS measures are normalised quantities, which are connected with determination of efficiency of various subsystems within the ASFEP, then maximum efficiency of the ASFEP is presented in the normalised form as well. Modelling of processes of decrease in the ASFEP efficiency and processes of subsequent rehabilitation of efficiency of the ASFEP is described by certain variants of the step continuous functions. In addition, the article describes propositions concerning kinds of approximation of the FS measures, which were included to the long-term plans, with the help of the specific exponential functions. These functions depend on the nature of the sources of financing, on the intensity of labour of the personnel, as well as on the nature of wear and tear of the fire-extinguishing equipment. The ASFEP model, which is subject of this investigation, includes 4 subsystems of the first level and 18 subsystems of the second level. Having accepted certain assumptions for the rehabilitation measures, we have simulated form of the graph of actual rehabilitation of the ASFEP efficiency in usual conditions. Several shares of efficiency of the FS measures within the general plan of the FEC object were described depending on the relevant conditions for three groups of parameters (time, financing, management).

There are many such generalisations in the article, which make it possible to communicate the generalised significance: duty shift, FS measures, fire-extinguishing equipment, import equipment, dangerous events, and so on. The formalised step dependence of the ASFEP efficiency for the linear nature of two subprocesses helps further to ensure correct simulation of forms of the approximating functions, which envelope moments of rehabilitation and destruction. The ASFEP has the sufficiently ramified structure with many various dependences. Each subsystem has its own plan of the FS measures. Method of formalisation helps to combine these uncoordinated plans into the single structure - matrix with certain parameters, provided that later on it would be possible to use this matrix in the course of description of the main model of assessment of the ASFEP efficiency. In addition to the abstraction procedure, this method makes it possible to make additions to the general process of modelling/simulation.

\section{RESULTS}

Before transfer to the mathematical expression of efficiency both of the certain measures of the FS maintaining, and of the entire ASFEP for usual conditions, let us present schematically temporal development of two subprocesses, which were described above. Hereinafter we will refer process of registration of prerequisites of the dangerous situations as the destructive subprocess, while the reverse subprocess we will refer as the creative subprocess. We will also assume that the ASFEP efficiency (which we will denote as W) depends on time, 


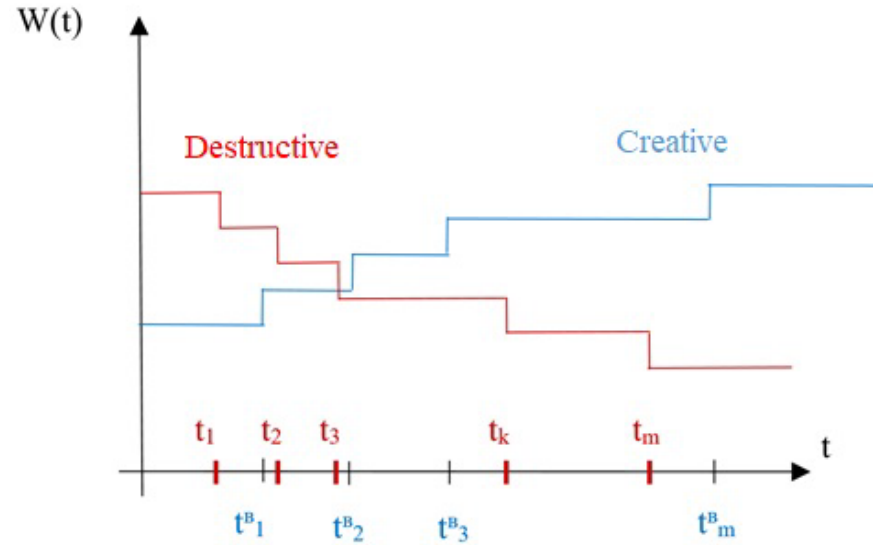

Figure 1: Decrease in the ASFEP efficiency in the course of the destructive subprocess and rehabilitation the ASFEP efficiency in the case of performance of creative measures

while decrease or rehabilitation of the ASFEP efficiency in the course of the above-described subprocesses we will denote as $\Delta \mathrm{W}$. In this case, if we will assume that both subprocesses have a linear nature, then we will obtain approximately such graphs (Figure 1).

The destructive subprocess and moments of registration of the dangerous events are marked in Figure 1 in red colour. Due to performance of measures of the creative subprocess (in Figure 1 it is marked in blue colour), rehabilitation of efficiency of the ASFEP operation is ensured in respect of the FS maintaining. Because of these two subprocesses, which were described above, have opposite directions in respect of the ASFEP efficiency, then the first of them creates the need in the measures, which must be planned for the future. The second subprocess ensures performance of the FS measures, which compensate for destructive action of events of the first subprocess. In addition, this subprocess ensures monitoring of and control over performance of these measures with the required efficiency. The rehabilitation measures as such can be represented by the component objects, which consist of many procedures and require certain planning in respect of time, financing, and resources.

In order to form the aggregate indicator of the ASFEP efficiency, let us introduce the following nominations. We will denote the maximum efficiency, which the ASFEP can have, as $W_{\max }$. Then, the ASFEP efficiency, which makes it possible to perform work operations in the course of the operational support of the FEC object in respect of the FS we will denote as $W_{\text {required }}$. At the same time, the maximum efficiency, which does not make it possible to perform work operations at the FEC object, we will denote as $W_{\text {critical }}$. Hereinafter we will refer them as maximum, required, and critical efficiencies, respectively. In this case, process of assessment of efficiency we will perform within the framework of the events, which are registered by the duty shift of the object: destructive events and creative events.

If we will use $M$ in order to denote quantity of all measures of the second process, performance of which will result in the situation, where the ASFEP efficiency will be equal to $W_{\text {max }}$, then it would be logical to present this measure in the normalised form as (Eq. 1):

$W_{\max }=\sum_{(i=1)}^{M} \alpha_{i} \beta_{i}=1$

where $\alpha_{i}$ is the importance of the $\mathrm{i}$-th measure; $\beta$ is the share of efficiency of the i-th measure in the general goal efficiency of the rehabilitation process (conventional $\Delta \mathrm{W}$ is determined for this process).

The condition was introduced on the reason of determination of efficiency of various subsystems of the ASFEP through the normalised dimensionless value. In order to form this value, measures from various plans are utilised, and each of these measures makes its contribution to the total efficiency of the ASFEP of the FEC object. Importance of each measure is normalised value as well. This importance can be determined by the experts in the FS sphere, if they would compare the data, which are necessary for the duty shift or for the programmes of support to management. Later on, these data will be summarised in tables in order to ensure utilisation of the obtained assessments in the subsystems of the software and of the mathematical support of the ASFEP. Procedure of obtaining these assessments and method of their assessment will be presented below.

In order to ensure confidence of the duty shift in respect of successfulness of the measures of the creative process, which are performed by the duty shift, efficiency of the entire ASFEP must be in the range between Wmax and Wcritical. Taking into account that the fire-extinguishing equipment has its own exploitation resource (operation life), as well as the fact that not only events (as such) of the destructive subprocesses, but durations of exploitation of the fire-extinguishing equipment between these events decrease efficiency of this equipment, it is possible to consider that the destructive subprocess is continuous in time. Decrease in the ASFEP efficiency, which is observed between the registered prerequisites of negative events, can be simulated with the help of the certain curve, form of which we will not present. Let us assume that in this case the destructive subprocess for the events from Figure 1 can be presented as follows (Figure 2).

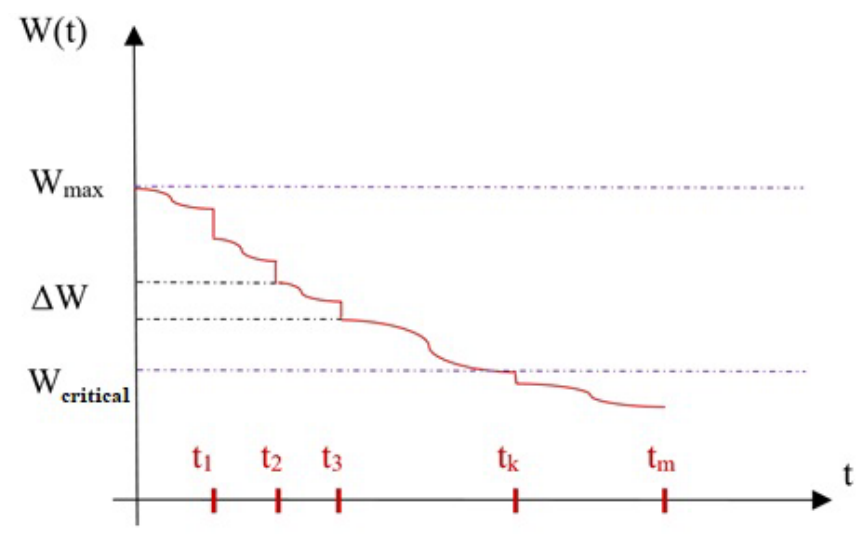

Figure 2: Variant of decrease in the ASFEP efficiency in the course of the destructive subprocess 
In the moment of registration of the potentially dangerous event, it is possible that the step fall of efficiency for the certain value can occur. Value $\Delta \mathrm{W}$ is fixed between two time points. Modelling of rehabilitation of the ASFEP efficiency and its certain subsystems in the course of performance of measures of the creative process also cannot be presented by the linear function. In all likelihood, this dependence will be presented as the step dependence, because of registration of rehabilitation of efficiency in the course of performance of the specific measure will be fixed in the certain moments of time in accordance with the above-listed documents.

However, taking into account the fact that performance of these measures is not implemented immediately, but during a certain time cycle of management, as well as taking into account that rehabilitation measures as such include the sequence of actions, which increase the ASFEP efficiency, it is possible to suppose that in order to model/simulate nature of their influence, it would be necessary to use the continuous curve of rehabilitation of efficiency (Figure 3). In this case, the measures, which were planned for performance in the long-term plans, can be approximated by the certain continuously increasing curve of rehabilitation of the ASFEP efficiency, which would envelope actual moments of rehabilitation.

One of variants of such enveloping function can be the function (Eq. 2), which is shown in Figure 3:

$W(t)=W_{\max }\left(1-e^{-\frac{t}{\lambda}}\right)$

where $T$ is a certain value, which depends on the nature of financing and/or on the intensity of labour of personnel.

As concerns the destructive subprocess, it is also possible to accept the exponential function (Eq. 3) of the following kind (Figure 4):

$W(t)=W_{\max } e^{-\frac{t}{\lambda}}$

where $\lambda$ is the certain value, which depends on the nature of wear and tear of the fire-extinguishing equipment.

In this case, the goal value for the aggregate indicator of the ASFEP efficiency in the course of performance of

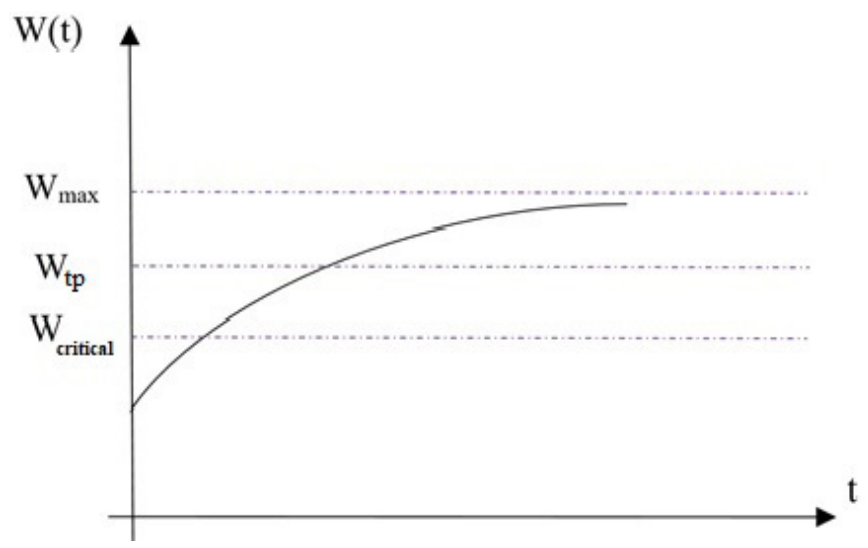

Figure 3: Variant of the enveloping function of rehabilitation of the ASFEP efficiency in the course of the creative subprocess

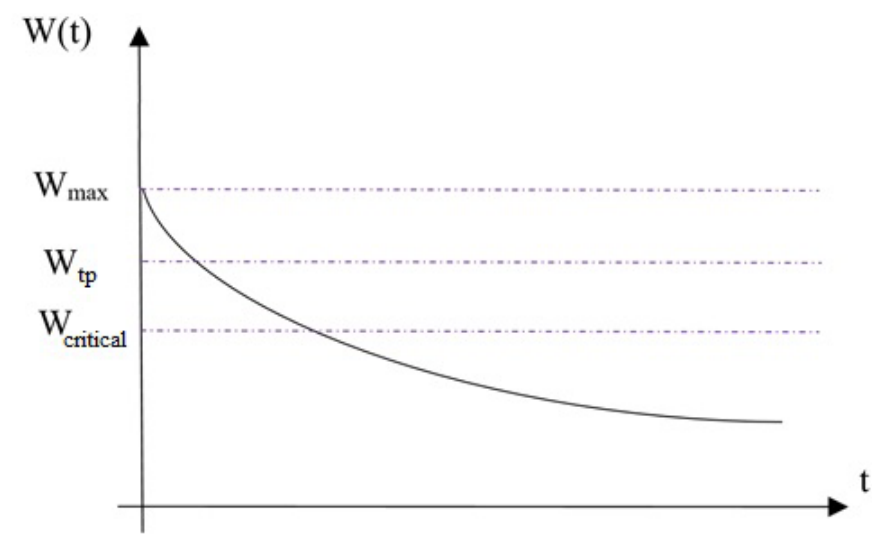

Figure 4: Variant of decrease in the ASFEP efficiency in the course of the destructive subprocess

the planned measures of the creative subprocess will be such value of function $\mathrm{W}(\mathrm{t})$, at which (Eq. 4):

$W(t) \geq W_{\text {required }}$

Continuation of the ASFEP operation at the value of the aggregate indicator of efficiency at the section is possible, however, at the essential restrictions (Eq. 5).

$W_{\text {required }} \geq W(t) \geq W_{\text {critical }}$

It is possible to assume that each plan of performance of rehabilitation measures within the creative subprocess is the conventional sum (or vector) of the measures, which are included to the relevant plan. If we will denote efficiency of the $\mathrm{j}$-th plan through $\beta^{j}$, then for each of such plans it is possible to write down (Eq. 6):

$\beta^{j}=\left\{\beta^{j}{ }_{1}, \beta^{j}{ }_{2}, \ldots, \beta^{j}{ }_{M^{j}}\right\}$

where $M^{i}$ is the quantity of measures in the j-th plan; $\beta_{i}^{j}$ is the share of efficiency of the i-th measure within the goal efficiency of the rehabilitation process in the j-th plan.

If we would assume that measures $\beta_{i}^{j}$ in the $j$-th plan are implemented in such a manner that end of the measure with sequential number $i$ denotes beginning of the measure with sequential number $i+1$ (with the certain delay), then, if we would assume that nature of the enveloping curve of rehabilitation in the course of performance of certain measures is similar with (2), while for the destructive subprocess it is similar with (3), then it is possible to present the graph of actual rehabilitation of the ASFEP efficiency in the course of the planned measures in usual conditions in the form as follows (Figure 5).

Having combined plans $\beta^{\wedge}$ j for all subsystem of the ASFEP of the second level into the single set of plans of the FEC object in respect of the FS measures, we will obtain matrix $B$, quantity of lines within which will be equal to quantity of plans and which will not be equal to quantity of columns (Eq. 7):

$B=\left[\begin{array}{ccc}\beta_{1}^{1}, \beta^{1} & \cdots & \beta^{1} \\ \vdots & \ddots & \vdots \\ \beta^{N}{ }_{1}, \beta^{N}{ }_{2} & \cdots & \beta^{N}{ }_{M^{N}}\end{array}\right]$

where $\mathrm{N}$ is the total quantity of plans within the creative subprocess of the ASFEP; $M$ is the vector of quantity of measures within each of these plans. 


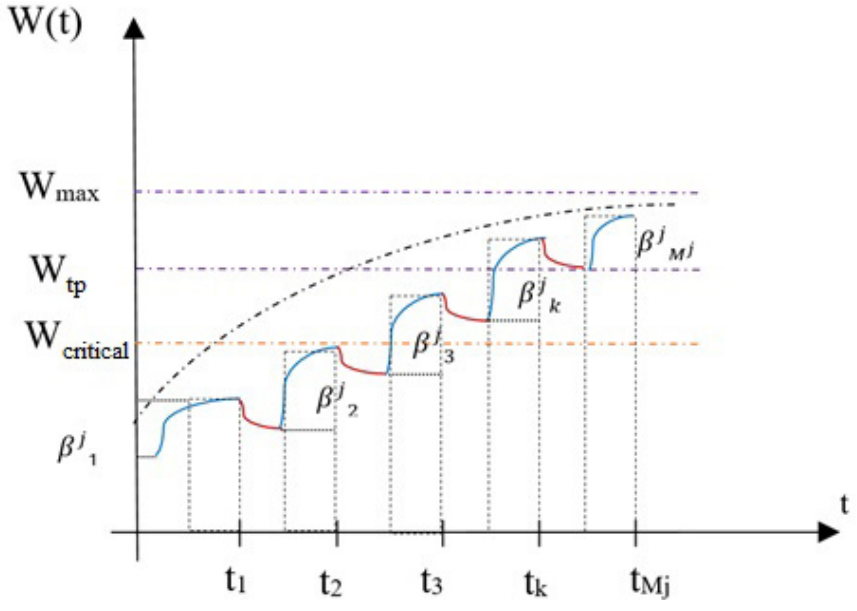

Figure 5: Graph of actual rehabilitation of the ASFEP efficiency in the course of the planned measures in usual conditions for the $j$-th plan (in accordance with the accepted assumptions concerning the nature of functions)

Shares of efficiency of the FS measures $\beta_{i}^{j}$ within the set of plans of the FEC object depend on the time and on financing, because of they must be planned and performed. In addition, it is necessary to ensure management of the measures within these plans. Therefore, it is possible to determine functions of shares of efficiency as the function with the following groups of parameters (Eq. 8):

$\beta_{i}^{j}=f\left(t^{i j}, \varphi_{i j}, U_{i j}\right)$

where $\mathrm{t}^{\mathrm{j}}$ is the time, which is required for performance of the i-th measure of the j-th plan, after the lapse of which efficiency $\beta_{i}^{j}$ will be achieved; $\varphi_{i j}$ is the financing, which is required for performance of the $i$-th measure of the $j$-th plan, in the case of complete identification of which efficiency $\beta$ i will be achieved; $U_{i}$ is the management, which is required for performance of the $\mathrm{i}$-th measure of the $\mathrm{j}$-th plan.

All three groups of parameters have the form of complex objects. Therefore, it is possible that it would be necessary to introduce certain hierarchies in order to ensure presentation of these objects [13]. In principle, all three groups of parameters are interdependent variables. However, we will not analyse this very comprehensive variant of solving the task of management in such statement of the problem. If to accept that management, time, and financing are independent variables (this assumption is valid for the relevant decision-makers of the duty shift of the FEC object), then it is possible to determine various values of functions $\beta_{i}^{j}$ by fixing two of three groups of these parameters. In this case, if financing is sufficient for performance of the rehabilitation measures and if it is complete for the i-th measure of the j-th plan, while management process ensures timely provision of finances to the function $\beta_{i}^{j}$, then it is possible to formulate the following determination (Eq. 9):

$\beta^{j}{ }_{i}(t, \varphi, U)=\left\{\begin{array}{c}0, t<t_{t p}^{i j} \\ \beta_{i}^{j p l}, t \geq t_{t p}^{i j}\end{array}\right.$ where $\beta_{i}^{j \mathrm{pl}}$ is the planned (in the course of performance) share of efficiency of the $i$-th measure of the $j$-th plan in the general efficiency of the creative process (maximum for this measure); $t_{t p} i$ is the time, which is required for the unconditional performance of the i-th measure of the j-th plan.

If we would analyse the situation, where there is sufficient time for performance of the measure $t_{t p}{ }^{i j}$ and management processes ensure time of its performance in full volume, then in the course of performance of the i-th measure of the $j$-th plan of the creative process during time $t_{t p}{ }^{i j}$ in the case of availability of various sources of financing of the measure of function $\beta_{i}^{j}$ it would be necessary to formulate such determination (Eq. 10):

$\beta_{i}^{j}(t, \varphi, U)=\left\{\begin{array}{c}0, \varphi_{i j}<\varphi_{r}^{i j} \\ \frac{\varphi_{i j}}{\varphi_{t p}^{i j}} \beta_{i}^{j \rho l}, \varphi_{r}^{j j}<\varphi_{i j}<\varphi_{t p}^{i j} \\ \beta_{i}^{j p l}, \varphi_{i j}=\varphi_{t p}^{i j}\end{array}\right.$

where $\varphi_{i j}$ is the current financing of the $i$-th measure of the j-th plan, which was made during the period of performance of the measure $t_{t p}^{i j} ; \varphi_{r}^{i j}$ is the actually received funds during period $t_{t p}{ }^{i j}$ of performance of the $\mathrm{i}$-th measure of the j-th plan, provided that these funds ensure efficiency, which is lesser than $\beta_{i}^{j p l} ; \varphi_{t p}^{i j}$ is the is the required funds (complete necessary amount of funds) for the unconditional performance of the $\mathrm{i}$-th measure of the $\mathrm{j}$-th plan.

In this case, financing of the i-th measure of the j-th plan can depend on the time or on other parameters (for instance, on management). Presence of the middle line in (10) supposes possibility of a partial financing of these measures. It is sufficiently common and usual practice. Finally, if to fix time and financing, then it would be possible to present dependence of functions $\beta_{i}$ from management in such a manner (Eq. 11)

$\beta^{j}{ }_{i}(t, \varphi, U)=\left\{\begin{array}{c}0, U_{t e k}^{i j}<U_{t p}^{i j} \\ \beta_{i}^{j i l}, U_{t e k}^{i j} \geq U_{t p}^{i j}\end{array}\right.$

where $U_{\text {tek }}^{i j}$ is the value, which characterises such management by the $\mathrm{i}$-th measure of the j-th plan, in accordance with which this measure will be performed during the entire period of time, which is required for the unconditional performance of this measure, as well as in accordance with which complete and necessary financing will be ensured for such unconditional performance; $U_{t p}{ }^{i j}$ is the "minimum necessary" management by the i-th measure of the j-th plan in order to ensure efficiency $\beta_{i}^{j p l}$. One of the variants for development of the value $U^{\text {tek }}$ can be the approach, which makes it possible to analyse management $U_{i j}$ by the i-th measure of the j-th plan as the binary vector (Eq. 12):

$U_{i j}=\left\{U_{i j}{ }^{1}, U_{i j}{ }^{2}, \ldots, U_{i j}{ }^{P}\right\}, U_{i j}{ }^{m}=\{0,1\}$

where $P$ is the quantity of the managing actions for the $\mathrm{i}$-th measure of the $\mathrm{j}$-th plan.

In principle, it would be necessary to take into account importance of each action; however, for the sake of simplicity we will consider that all procedures within the set of 
actions of the i-th measure of the j-th plan are important in the same manner. Then (Eq. 13):

$U_{\text {tek }}^{i j}=\sum_{m=1}^{P} U_{i j}^{m}$

It is possible to determine value of the aggregate indicator of the ASFEP efficiency in the course of performance of the measures of the creative process through the sum of the planned shares of efficiency of measures within all plans of the creative process in usual conditions (Eq. 14):

$W(t, \varphi, U)=\Sigma_{j=1}^{N} \Sigma_{i=1}^{M^{j}} \beta^{j}{ }_{i}(t, \varphi, U)$

for conditions (Eq. 15):

$$
\left\{\begin{array}{c}
W(t, \varphi, U) \leq 1 \\
W(t, \varphi, U) \geq W_{t p} \\
\sum_{j=1}^{N} \sum_{i=1}^{M^{j}} \beta_{i}^{j p l}=1 \\
\bigcup_{t e k}^{i j} \geq \bigcup_{t p}^{i j}
\end{array}\right.
$$

It is possible to determine influence of the destructive process in usual conditions through action on the components of subsystems of the ASFEP in such a manner (Eq. 16):

$V=\left\{\gamma_{1}, \gamma_{2}, \ldots, \gamma_{L}\right\}$

where $Y_{i}$ is the i-th action on the component of the subsystem of the ASFEP, provided that this action causes the loss in the general efficiency as a result of the destructive process, as well as provided that this action transfers the ASFEP of the FEC object into new state with the lesser efficiency (by $Y_{i}$ value); $L$ is the total quantity of negative actions in the course of the destructive process.

In this case (Eq. 17):

$\sum_{i=1}^{L} \gamma_{i}=1$

Then, total value of the aggregate indicator of efficiency in the case of action of two subprocesses within the ASFEP in usual conditions in the course of the FS measures will be determined in such a manner in the case of compliance with the conditions $(15,16)$, (Eq. 18):

$W(t, \varphi, U)=\sum_{j=1}^{N} \Sigma_{i=1}^{M^{j}} \beta^{j}{ }_{i}(t, \varphi, U)-\Sigma_{k=1}^{L} \gamma_{k}$

For the purposes of management of the efficiency of the ASFEP at the FEC object, there are good reasons to use such dimensionality for $L$, which will be comparable with the total quantity of the measures of all plans (Eq. 19).

$L \approx \sum_{i=1}^{N} M^{i}$

If we would analyse influence of the special conditions upon the measure of the ASFEP efficiency, it is possible to state that these conditions will result in the changes of $t_{t p}^{i j}, U_{t p}^{i j}$ and $\varphi_{t p}^{i j}$.

\section{Discussion}

The time, which is required for performance of the i-th measure of the j-th plan, can include both periods of purchase of the required spare parts of equipment for the ASFEP, and periods of performance of technical maintenance of components of various subsystems of the ASFEP. In the case of availability of any restrictions, which are connected with the special conditions, it is possible that the required import equipment will not be purchased, and that technical maintenance of any components will not be provided. In this case, $\beta_{i}^{\text {jpl }}$ will not be obtained even in the event where $t \geq t_{t p}^{i j}$. The same words it is possible to say concerning updates of the relevant software applications. Such influence is especially noticeable in the case of application of "Industries 4.0" analytical tools [14, 15]. There are many situations, where import substitution is practically not envisaged for the FEC objects, because of the required systems of the FS maintaining are integrated into the technological chains of the production processes and they form the organic whole with the already purchased state-of-the-art processing technologies.

In this case, it should be necessary to pay attention to the fact that as of today systems of control and maintaining the fire safety at the FEC enterprises include components of equipment of foreign production [16, 17]. In accordance with information, which is presented in article [18], $80 \%$ of the market of the fire-fighting protection facilities in 2018 is occupied by the foreign manufacturing companies. Market shares in respect of volume of products are as follows: "Arton" Private Enterprise (36 \%), Beijing PT Security Technology (33\%), Wizmart Technology $(11 \%)$. Distribution of shares in value terms: Bosch (11\%), Hekatron (9\%), Honeywell (8\%) [18].

The financing, which is required for performance of the i-th measure of the j-th plan, in the case of availability of the imported components within subsystems of the ASFEP cannot ensure (in the special conditions) achievement of the required share of efficiency $\beta_{i}^{j p l}$ to the full extent. Such financing is frequently inaccessible or utilisation of such financing does not provide possibilities for purchases of the required components due to the established economic sanctions, or it is difficult to ensure performance of the required technical maintenance of the imported equipment by the supplier of this equipment due to the same reason (economic sanctions).

In addition, the management, which is required for performance of the i-th measure of the j-th plan, in the special conditions can ensure only a certain part of the procedures, which must be performed (12) as compared with the total quantity of the required procedures. Therefore, result of application of the special conditions as compared with usual conditions is connected with the following fact: values of functions $\beta_{i}^{j}$ in the special conditions become in many cases equal to 0 in the situations, where in usual conditions they have ensured $\beta_{i}^{j p l}$. Therefore, the required value of indicator of efficiency in the course of performance of measures of the creative process is not achieved, and the required level of the ASFEP efficiency is not implemented. Consequently, for the special conditions it is possible to conclude that (Eq. 20):

$W_{u s}(t, \varphi, U)>W_{s p}(t, \varphi, U)$

where $W_{u s}(t, \varphi, U)$ is the measure of the ASFEP efficiency in the course of performance of the complex of measures of the creative process in usual conditions; $W_{s p}(t, \varphi, U)$ is the measure of the ASFEP efficiency in the course of 
performance of the complex of measures of the creative process in the special conditions.

Duration of performance of each measure of various plans is frequently the fixed value, which is determined in the normative documents concerning management. As a rule, changes in the sources of financing the measures of various plans in the special conditions also cannot be used for overcoming this situation (20). Consequently, the most natural method, which would ensure overcoming this situation, is to develop such methods of support to management, which would compensate for total decrease in the ASFEP efficiency, if such decrease was caused by occurrence of the special conditions following operation in usual conditions.

One of such methods, which ensures increase in quality of support to management and which supports increase in values of the indicator of the ASFEP efficiency of the FEC objects in the special conditions, is the set of methods of strategic planning [19]. This direction can be based on both the already developed methods [20] and on the newly developed methods as well. Development of these methods with the purpose of support to the ASFEP management must result in overcoming the trend of decrease in efficiency of the ASFEP operation in the special conditions. The desired goal must be established as follows: to develop the aggregate indicator of quality in the multilevel sequence of solutions and actions, provided that such sequence can be dynamically changed in order to achieve the required result by analogy with the result, which was elaborated in the articles [13, 20, 21]. This would make it possible to perform a number of generalisations of the general nature and ensure application of this result in other spheres of science and technology. This set of methods, which is considered as the supporting tool of the ASFEP management, must be included to the system of the specialised software of the ASFEP maintaining on the basis of the solutions, which are proposed by domestic engineers and scientists [22-24]. In this case, application of these solutions will be the most efficient due to decrease in influence of the human factor upon the software at the stage of its development.

\section{CONCLUSIONS}

Undoubtedly, for a safe and uninterrupted technological process, an important role is played by ways of improving and modernising ASFEP operating at the FEC. The article clearly illustrates that one of the most important methods of improving the quality of management support, ensuring an increase in the value of the efficiency indicator of ASFEP of the fuel and energy complex in special conditions, is a set of strategic planning methods. It allows the expedient conducting of BOP activities in a creative subprocess during the operation of ASFEP at the FEC facilities. Represented mathematical expression of the efficiency of the FS events allows conducting the analysis of ASFEP in general in order to identify problematic processes in the automation of fire protec- tion of FEC facilities and to make timely decisions to correct them or eliminate them completely. Functional dependencies of shares of efficiency of these measures in the plan of FEC facilities on the period of performance of these measures, on their funding and management have been established. Reviewing of the task of management in the interdependence of all three groups of parameters may be the subject of a new study.

\section{REFERENCES}

1. Castillo-Landero, A., Ortiz-Espinoza, A.P., Jiménez-Gutiérrez, A. (2019). A process intensification methodology including economic, sustainability, and safety considerations. Industrial and Engineering Chemistry Research, vol. 58, no. 15, 6080-6092.

2. Tagiev, R.M. (2014). Modern technologies of fire protection on guard of objects of ACS "Gazprom". Gas Industry, no. 712, 70-73.

3. Beata, P.A., Jeffers, A.E., Kamat, V.R. (2018). Real-time fire monitoring and visualization for the post-ignition fire state in a building. Fire Technology, vol. 54, no. 4, 995-1027.

4. Medina-Herrera, N., Tututi-Avila, S., Jiménez-Gutierrez, A. (2019). A new index for chemical process design considering risk analysis and controllability. Computer Aided Chemical Engineering, vol. 46, 373-378.

5. Ortiz-Espinoza, A.P., Kazantzi, V., Eljack, F.T., Jiménez-Gutiérrez, A., El-Halwagi, M.M., Kazantzis, N.K. (2019). Framework for design under uncertainty including inherent safety, environmental assessment, and economic performance of chemical processes. Industrial and Engineering Chemistry Research, vol. 58, no. 29, 13239-13248.

6. Allason, D., Medina, C.H., Johnson, D.M., Pekalski, A., Dutertre, A., Mansfield, D. (2019). Explosion safety gap reduction with water curtain. Journal of Loss Prevention in the Process Industries, vol. 61, 66-81.

7. Zhang, Y., Zhang, M., Qian, C. (2018). System dynamics analysis for petrochemical enterprise fire safety system. Procedia Engineering, vol. 211, 1034-1042.

8. Tagiev, R.M. (2017). Fire safety of objects of fuel and energy complex: the category of professional and moral. The opinion of the business. Safety of Buildings and Structures, no. 2, 232-237.

9. Wang, L.-Q., Ma, H.-H., Shen, Z.-W. (2020). Explosion characteristics of $\mathrm{H} 2 / \mathrm{N} 2 \mathrm{O}$ and $\mathrm{CH} 4 / \mathrm{N} 2 \mathrm{O}$ diluted with N2. Fuel, vol. 260, article number 116355.

10. Fleming, R.P. (2016). Automatic sprinkler system calculations. Springer, New York.

11. Topolskiy, N.G., Samarin, I.V., Strogonov, A.Yu. (2018). Technique of an assessment of efficiency of management of fire safety at facilities of fuel and energy complex using by computer-aided support control system. Fire and Explosion Safety, vol. 27, no. $12,19-26$. 
12. GOST R ISO 9000:2015. Quality management systems. Fundamentals and vocabulary. (2015). Standardinform, Moscow. http://docs.cntd.ru/document/1200124393

13. Li, G., Wang, X., Xu, H., Liu, Y., Zhang, H. (2019). Experimental study on explosion characteristics of ethanol gasoline-air mixture and its mitigation using heptafluoropropane. Journal of Hazardous Materials, vol. 378, article number 120711.

14. Vaidya, S., Ambad, P., Bhosle, S. (2018). Industry 4.0 - A glimpse. Procedia Manufacturing, vol. 20, 233-238.

15. Zezulka, F., Marcon, P., Vesely, I., Sajdl, O. (2016). Industry 4.0 - An introduction in the phenomenon. IFAC-Papers OnLine, vol. 49, no. 25, 8-12.

16. Pei, B., Yang, Y., Li, J., Yu, M.-G. (2018). Experimental study on suppression effect of inert gas two fluid water mist system on methane explosion. Procedia Engineering, vol. 211, 565-574.

17. Pei, B., Wei, S., Chen, L., Pan, R., Yu, M., Jing, G. (2019). Synergistic inhibition effect on the self-acceleration characteristics in the initial stage of methane/ air explosion by $\mathrm{CO} 2$ and ultrafine water mist. RSC Advances, vol. 9, no. 24, 13940-13948.

18. Granum, H., Aune, V., Børvik, T., Hopperstad, O.S. (2019). Effect of heat-treatment on the structural response of blast-loaded aluminum plates with pre-cut slits. International Journal of Impact Engineering, vol. 132, article number 103306.
19. Samarin, I.V., Fomin, A.N. (2014). Strategic planning at the enterprise: application of a method of the analysis of hierarchies to analyze target system installations. Innovation and Investment, no. 6, 132-141.

20. Samarin, I.V. (2014). Formalization of the problem of the justification of the medium-term action plan to build the automated control system of strategic planning at the enterprise. Innovation and Investment, no. 4, 177-183.

21. Grisaro, H.Y., Benamou, D., Dancygier, A.N. (2018). Investigation of blast and fragmentation loading characteristics. Engineering Structures, vol. 167, 363-375.

22. opolsky, N.G., Kruchkov, A.V., Grachev, D.S., Mikhaylov, K.A., Zuy, N.L. (2017). Synthesis of typical software modules for computer-aided fire-explosion safety system. Technology of Technosphere Safety, no. 6(76), 56-64.

23. Butuzov, S.Yu., Kryuchkov, A.V., Samarin, I.V. (2018). The stability of the software in the automated system of fire and explosion. Modern Science: Actual Problems of Theory and Practice. Series: Natural and Technical Sciences, no. 9, 50-54.

24. Kruchkov, A.V. (2015). Specifications requirements for special software as information storage unit passport. Technology of Technosphere Safety, vol. 6 , no. $64,175-180$. 